\title{
ANALISA PERENCANAAN PONDASI TIANG PANCANG PADA GEDUNG REKTORAT UNIVERSITAS DARUL ULUM JOMBANG
}

\author{
Mualif*1, Ahmad Ridwan ${ }^{2}$, Sigit Winarto ${ }^{3}$ \\ ${ }^{1,2,3}$ Fakultas Teknik, Universitas Kadiri \\ email : *1 alifsipil15@gmail.com , ${ }^{2}$ ahmad ridwan@unik-kediri.ac.id, \\ ${ }^{3}$ sigit.winarto@unik-kediri.ac.id.
}

\begin{abstract}
The building is a physical form of the results of construction work that integrates with its domicile. The building functions as a place to live and as a public place like a place of education. As is the case with buildings in general, Darul Ulum University's Rectorate Building in Jombang has a variety of functions, including a venue for various activities both for the chancellor, education staff, and students. In this research, the writer wants to plan the construction of Darul Ulum University, Jombang University Building, with a pile foundation using the Guy Sangrelat method based on SPT data obtained from the project construction site. The pile foundations' design received a vertical load of 36 tons, carrying capacity of a single pile of 12.23 tons, carrying capacity of a group pile foundation of 37 tons, carrying capacity of a pile foundation 37 tons greater than the load that rests on the foundation. The foundation plan used in the Darul Ulum Jombang University Rectorate Building construction is to use a $30 \mathrm{~cm}$ diameter pile with a depth of 9.6 meters.
\end{abstract}

Keywords : Building, Guy Sangrelat, Pile Foundation, Building Construction

\begin{abstract}
Abstrak
Gedung merupakan wujud fisik hasil pekerjaan konstruksi yang menyatu dengan tempat kedudukannya. Gedung berfungsi sebagai tempat hunian dan sebagai tempat umum seperti tempat pendidikan. Seperti halnya dengan Gedung pada umumnya, Gedung Rektorat Universitas Darul Ulum Jombang mempunyai berbagai fungsi meliputi tempat terselenggaranya berbagai kegiatan baik untuk rektor, tenaga kependidikan maupun kemahasiswaan. Pada penelitian ini penulis ingin merencanakan pembangunan Gedung Rektorat Universitas Darul Ulum Jombang dengan pondasi tiang pancang dengan metode Guy Sangrelat berdasar data SPT yang diperoleh dari lokasi pembangunan proyek. Rencana pondasi tiang pancang didapatkan beban vertical sebesar 36 ton, daya dukung tiang tunggal sebesar 12.23 Ton, daya dukung pondasi tiang kelompok sebesar 37 ton, daya dukung pondasi tiang pancang 37 Ton lebih besar dari beban yang menumpu pada pondasi. Rencana pondasi yang digunakan pada pembangunan Gedung rektorat Universitas Darul Ulum Jombang adalah menggunakan tiang pancang berdiameter $30 \mathrm{~cm}$ dengan kedalaman 9.6 meter.
\end{abstract}

Kata Kunci : Gedung, Guy Sangrelat, Tiang Pancang, Konstruksi Bangunan 


\section{PENDAHULUAN}

Fasilitas ruangan untuk menjalankan suatu pendidikan sangatlah penting dalam hal menunjang aktivitasnya, [1][2]. Salah satu faktor keberhasilan suatu institusi pendidikan, [3][4] sangat di tentukan dari bagaimana perencanaan ruangan dalam hal menunjang aktivitas baik dari segi keamanan dan juga kenyamanan, faktor keamanan sangat ditentukan dari mulai awal perencanaan suatu pondasi sebagai tumpuan awal suatu bangunan [5]. Perkembangan konstruksi bangunan yang pesat di Indonesia [6][7][8] memandang pondasi salah satu bagian yang sangat penting maka terkait dengan hal itu, dalam penelitian ini[9][10] pada item struktur pondasi (tiang pancang) pada Gedung Rektorat Universitas Darul Ulum yang terletak di Kelurahan Mojongapit Kecamatan Jombang, merupakan gedung tipe rangka pemikul momen khusus dengan luasan21,60 $\mathrm{m} \times$ 43,20 $\mathrm{m}$.

Pada penelitian ini penulis akan menghitung pembebanan, daya dukung tiang pancang beserta kebutuhan tiang pancang kelompok. Perencanaan pondasi tiang dihitung secara manual menggunakan beberapa metode sesuai dengan peraturan-peraturan yang telah ditetapkan. Tahapan perhitungan dimulai dengan informasi perencanaan struktur, gaya-gaya yang bekerja pada pondasi, penentuan dimensi tiang, perhitungan jumlah tiang pondasi, efisiensi kelompok tiang control terhadap beban vertikal yang bekerja, control terhadap beban horizontal yang bekerja, penentuan pondasi dan penulangan pile cap [11].

\section{METODE PENELITIAN}

\subsection{Metode Pengumpulan dan Pengolahan Data.}

Pengumpulan data ini diperoleh dari hasil survey lapangan secara langsung dan dari instansi yang terkait. Data-data yang dimaksudkan sebagai berikut :

A. Study literatur

Study literatur adalah proses pengumpulan data dari berbagai sumber referensi terkait dengan pondasi, jurnal, dan penelitian yang telah dilakukan yang berkaitan dengan pondasi. Data yang didapat dari studi literatur ini akan digunakan sebagai acuan untuk membuat penelitian

B. Metode Observasi dan Pengumpulan Data teknis

Pada tahapan ini dilakukan pengumpulan data teknis Gedung rektorat dan meninjau langsung ke lokasi proyek untuk mengetahui bagaimana kondisi proyek tersebut di lapangan. Adapun jenis-jenis data yang di gunakan adalah data yang di dapat dari tinjauan literatur terkait perencanaan pondasi yang sesuai dengan kondisi di lapangan. 
Adapun data-data yang di peroleh di lapangan adalah sebagai berikut :

Nama Bangunan : Gedung rektorat 3 Lantai.

Fungsi Bangunan : Ruang Kepala Biro, Hall, Ruang Rektor dan Ruang Sekretariat.

Luas Bangunan $\quad$ : $21,60 \mathrm{M} \mathrm{x} 43,20 \mathrm{M}$.

Komponen struktur : Struktur bawah ( Tiang Pancang).

Struktur atas : Baja dan Beton Bertulang.

\subsection{Alur Penelitian.}

Adapun tahapan alur penelitian yang akan dilakukan dalam analisis data adalah dengan sebagai berikut :

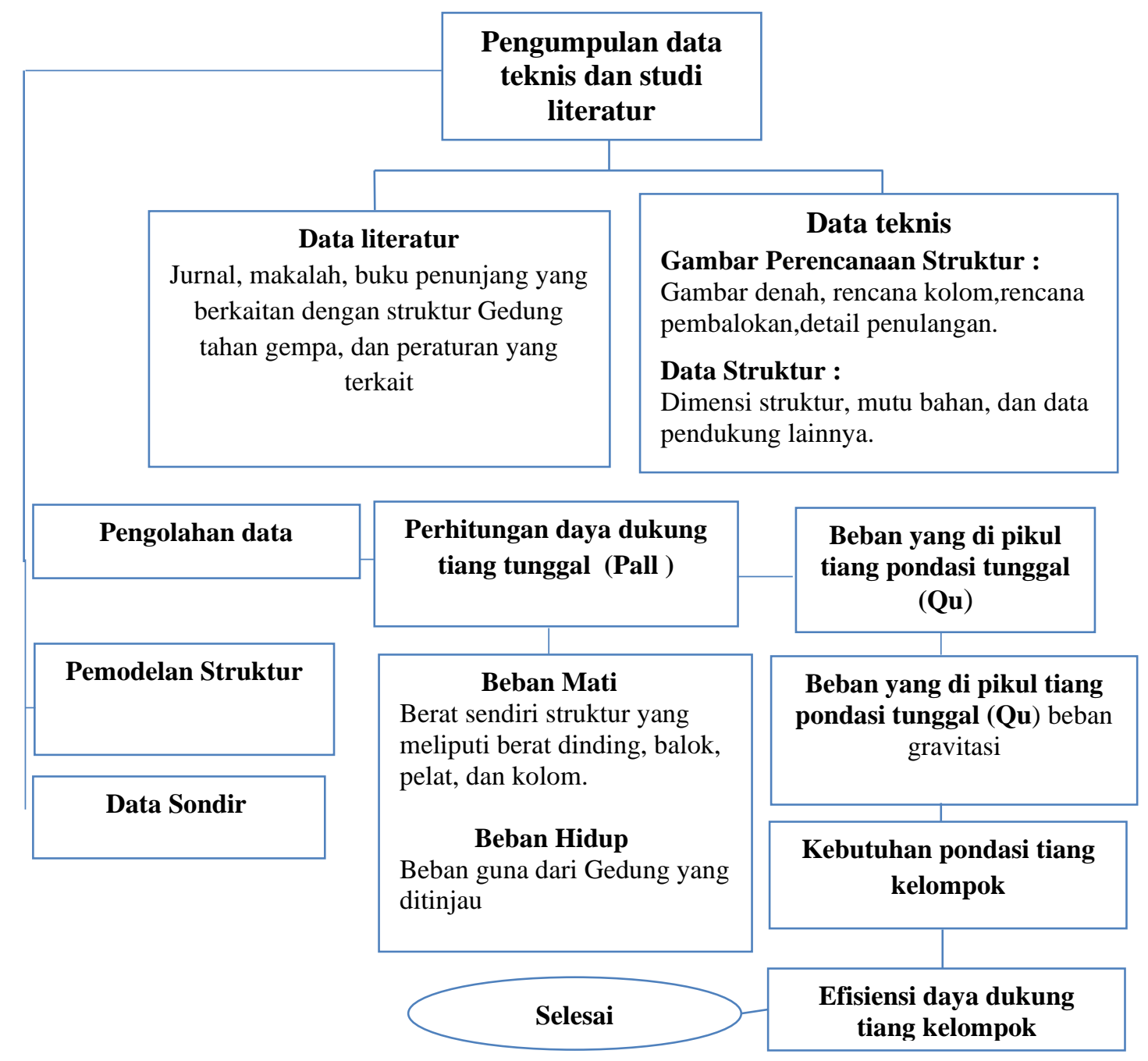

Sumber : Analisa Alur Penelitian

Gambar 1. Alur Penelitian. 


\section{HASIL DAN PEMBAHASAN}

\subsection{Perhitungan Pembebanan.}

A. Beban Mati.

Beban mati pada struktur bangunan ditentukan dengan menggunakan berat jenis bahan bangunan dengan berdasarkan Peraturan Perencanaan Pembebanan untuk Rumah dan Gedung 1987 dan unsur-unsur yang diketahui seperti pada denah arsitektur dan struktur. Beban-beban yang diakibatkan oleh gravitasi yang bersifat permanen dalam hal ini berat sendiri struktur. Selain ditentukan oleh kekakuan, perilaku dinamik bangunan juga sangat ditentukan oleh massa bangunan. Massa bangunan dalam hal ini akan sangat ditentukan oleh beban gravitasi yang bekerja. [12]

Dari hasil perhitungan didapatkan hasil pembebanan. Hasilnya dapat dilihat pada

Tabel 1.

Tabel 1. Perhitungan Pembebanan Lantai 3.

\begin{tabular}{|c|c|c|c|c|c|c|c|}
\hline $\begin{array}{l}\text { Beban Yang } \\
\text { Dihitung }\end{array}$ & $P$ & $L$ & $T$ & $\begin{array}{l}\text { Vol } \\
\left(M^{3}\right)\end{array}$ & Jumlah & $\begin{array}{c}\text { Berat Jenis } \\
\left(\mathrm{Kg} / \mathrm{M}^{3}\right)\end{array}$ & $\begin{array}{c}\text { Berat } \\
\text { Beban } \\
(\mathrm{Kg})\end{array}$ \\
\hline Kolom 1 & 0,50 & 0,5 & 2 & 0,511 & 14 & 2400 & 16.800 \\
\hline Kolom 2 & 0,25 & 0,3 & 2 & 0,125 & 14 & 2400 & 4200 \\
\hline Ring balok & 0,20 & 0,2 & 63,1 & 2,524 & 2 & 2400 & $12.115,2$ \\
\hline Balok 1 & 0,35 & 0,7 & 40,2 & 9,849 & 1 & 2400 & $23.637,6$ \\
\hline Balok2 & 0,25 & 0,4 & 63,1 & 6,311 & 1 & 2400 & 15.144 \\
\hline Balok 3 & 0,20 & 0,3 & 52,8 & 3,165 & 1 & 2400 & 7.596 \\
\hline Pelat & 216,6 & & 0,1 & 25,992 & 1 & 2400 & $62.380,8$ \\
\hline \multirow{2}{*}{\multicolumn{6}{|c|}{ Total }} & Jumlah & $141.873,6$ \\
\hline & & & & & & Jumlah & 141,8736 \\
\hline
\end{tabular}

Sumber : Analisa Perhitungan Beban Lantai 3.

Setelah didapatkan hasil penghitungan beban mati pada lantai 3 maka langkah selanjutnya yaitu menghitung beban mati pada lantai 2. pada penghitungan lantai 2 ini dilakukan dengan menghitung beban pada kolom-kolom, balok, dan juga plat lantai yang mana pada lantai 2 ini terdapat ruangan tengah yang direncanakan kosong/void. Hasil dari penghitungan ini tertulis dalam Tabel 2. 
Tabel 2. Perhitungan pembebanan lantai 2.

\begin{tabular}{|l|r|r|r|r|r|r|c|}
\hline $\begin{array}{c}\text { Beban Yang } \\
\text { Dihitung }\end{array}$ & $P$ & $L$ & $T$ & $\begin{array}{c}\text { Vol } \\
\left(M^{3}\right)\end{array}$ & Jumlah & $\begin{array}{c}\text { Beratjenis } \\
(\mathrm{Kg} / \mathrm{M} 3)\end{array}$ & $\begin{array}{c}\text { Berat } \\
\text { Beban } \\
(\mathrm{Kg})\end{array}$ \\
\hline Kolom 1 & 0,50 & 0,5 & 4,5 & 1,125 & 16 & 2400 & 43.200 \\
\hline Kolom 2 & 0,25 & 0,3 & 4,5 & 0,281 & 4 & 2400 & 2.700 \\
\hline Kolom 3 & 0,40 & 0,4 & 4,5 & 0,721 & 25 & 2400 & 43.200 \\
\hline Balok 1 & 0,35 & 0,7 & 40,2 & 9,849 & 1 & 2400 & $23.637,6$ \\
\hline Balok 2 & 0,25 & 0,4 & 40,2 & 4,022 & 1 & 2400 & 9,65 \\
\hline Balok 3 & 0,20 & 0,3 & 40,2 & 2,412 & 1 & 2400 & $5.788,8$ \\
\hline Balok 4 & 0,20 & 0,2 & 0,2 & 0,008 & 1 & 2400 & 19,2 \\
\hline Plat & 518,8 & 0,1 & 2,15 & $1.115,42$ & 1 & 2400 & $2.677,008$ \\
\hline & & & & & & Jumlah & $128.193,6$ \\
\hline & & & & & & Jumlah & 128,1936 \\
\hline
\end{tabular}

Sumber : Analisa Perhitungan Beban Lantai 2.

Setelah mendapatkan hasil penghitungan beban mati pada lantai 2, selanjutnya melakukan penghitungan beban lantai 1 , pada penghitungan lantai 1 beban sedikit lebih berkurang karena beban lantai injak didistribusikan langsung ke tanah yang ada di bawahnya.

Tabel 3. Perhitungan pembebanan lantai 1 .

\begin{tabular}{|l|c|c|c|c|c|c|c|}
\hline $\begin{array}{c}\text { Beban Yang } \\
\text { Dihitung }\end{array}$ & $\mathrm{P}$ & $\mathrm{L}$ & $\mathrm{T}$ & $\begin{array}{c}\text { Vol } \\
(\mathrm{M} 3)\end{array}$ & Jumlah & $\begin{array}{c}\text { Berat jenis } \\
(\mathrm{Kg} / \mathrm{M} 3)\end{array}$ & $\begin{array}{c}\text { Berat } \\
\text { Beban } \\
(\mathrm{Kg})\end{array}$ \\
\hline Kolom 1 & 0,50 & 0,5 & 4,5 & 1,13 & 16 & 2400 & 43.200 \\
\hline Kolom 2 & 0,40 & 0,4 & 4,5 & 0,72 & 25 & 2400 & 43.200 \\
\hline Kolom 3 & 0,30 & 0,3 & 4,5 & 0,41 & 4 & 2400 & 3.888 \\
\hline Sloof 1 & 0,25 & 0,4 & 252 & 251,50 & 1 & 2400 & 603.600 \\
\hline Sloof 2 & 0,30 & 0,6 & 40,2 & 7,24 & 1 & 2400 & $17.366,4$ \\
\hline & & & & & Jumlah & $711.254,4$ \\
\cline { 2 - 8 } & & & & Jumlah & 711,2544 \\
\hline
\end{tabular}

Sumber : Analisa Perhitungan Beban Lantai 1. 


\section{B. Beban Hidup.}

Berat sendiri dari bahan - bahan bangunan penting dan dari beberapa komponen gedung yang harus ditinjau di dalam menentukan beban mati dari suatu gedung, harus diambil menurut Tabel 1. Tabel 2. dan Tabel 3. [13]. Beban hidup yang diperhitungkan adalah sebagai berikut :

- Lantai biasa $\quad: 250 \mathrm{Kg} / \mathrm{M}^{2}$

- Lantai dek : $100 \mathrm{Kg} / \mathrm{M} 2$

Berdasarkan SNI 1727 : 2012 Pasal 4.8 semua beban hidup merata pada lantai dapat direduksi, kecuali untuk beban hidup merata pada atap [14].

- Beban HidupLantai 3 = Luas Lantai $\mathrm{x}$ Beban hiduprencana

$$
=216.6 \mathrm{M}^{2} \text { × } 250 \mathrm{Kg} / \mathrm{M}^{2}=54.150 \mathrm{~kg}
$$

- Beban HidupLantai $2=$ Luas Lantai $\mathrm{x}$ Beban hidup rencana

$$
=518.8 \mathrm{M}^{2} \text { X } 250 \mathrm{Kg} / \mathrm{M}^{2}=129.700 \mathrm{Kg}
$$

- Jumlah Beban Hidup = Beban hiduplantai $3+$ Beban Hiduplantai 2

$$
=54.150+129.700 \quad=183,85 \mathrm{Kg}
$$

Beban hidup diperhitungkan berdasarkan pendekatan matematis dan menurut kebiasaan yang berlaku pada pelaksanaan konstruksi di Indonesia. Untuk menentukan secara pasti beban hidup yang bekerja pada suatu lantai bangunan sangatlah sulit, dikarenakan fluktuasi beban hidup bervariasi, tergantung dan banyak factor, [15]. Adapun jumlah beban total yang menumpang di atas pondasi adalah sebagai berikut :

$$
\begin{array}{rlrl}
\text { - Beban Mati }=\text { Lantai } 3 & =141,8736 & \text { Ton. } \\
\text { Lantai } 2 & =128,1936 \text { Ton. } \\
\text { Lantai } 1 & =711,2544 \text { Ton. } \\
\text { Total } & =981,3216 \text { Ton. }
\end{array}
$$

- Beban Hidup =Lantai $3=54 \quad$ Ton.

$$
\begin{aligned}
& \text { Lantai } 2=129,5 \quad \text { Ton. } \\
& \text { Lantai } 1=129,5 \quad \text { Ton. } \\
& \text { Total }=313 \quad \text { Ton. }
\end{aligned}
$$

Dengan faktor keamanan = Jumlah Beban Mati dan Beban Hidup dikalikan 30\%

$$
=388,296 \text { Ton. }
$$

Sehingga

- Total beban

$=1.682,618$ Ton.

- Jumlah Pondasi

$=47$ bh.

- Beban 1 Tiang

$$
=36 \text { Ton. }
$$


Tabel 6. Data Sondir.

\begin{tabular}{|c|c|c|}
\hline $\begin{array}{l}\text { Kedalaman } \\
\text { (M) }\end{array}$ & Tahanan Ujung Tiang & Total Lekatan Lateral \\
\hline 1,2 & 35 & 40 \\
\hline 2,4 & 15 & 122 \\
\hline 3,6 & 7 & 166 \\
\hline 4,8 & 15 & 216 \\
\hline 6 & 17 & 270 \\
\hline 7,2 & 17 & 334 \\
\hline 8,4 & 35 & 434 \\
\hline 9,6 & 15 & 490 \\
\hline 10,8 & 10 & 530 \\
\hline 12 & 2 & 554 \\
\hline 13,2 & 1 & 564 \\
\hline 14,4 & 2 & 576 \\
\hline 15,6 & 1 & 586 \\
\hline
\end{tabular}

Sumber : Data Hasil Uji Sondir Proyek Pekerjaan Pembangunan Gedung Rektorat

Universitas Darul Ulum.

Pengujian dilakukan dengan mendorong konus (kerucut) kedalam tanah dan perlawanan tanah terhadap ujung konus maupun lekatan tanah terhadap selimut batang konus diukur, sehingga didapatkan nilai tahanan ujung (qc) dan lekatan selimut (fs), [16].

\subsection{Perhitungan Daya Dukung Pondasi}

Dalam perencanaan struktur atas dan struktur bawah suatu gedung terhadap pengaruh Gempa Rencana, struktur bawah tidak boleh gagal lebih dahulu dari struktur atas. Untuk itu, terhadap Pengaruh Gempa Rencana unsur-unsur struktur bawah harus tetap berperilaku elastik penuh, tak bergantung pada tingkat daktilitas yang dimiliki struktur atasnya. [17] 
Analisis daya dukung ijin tekan pondasi tiang terhadap kekuatan tanah mempergunakan formula Berdasarkan data sondir (Guy Sangrelat) dengan rumus :

$$
\text { Pall }=\frac{\text { qc X Ap }}{\text { FK1 }}+\frac{\text { Tf X Ast }}{\text { FK2 }} .
$$

Hasil perhitungan kemudian dilakukan seperti di bawah ini :

- Kedalama n 1,2 meter

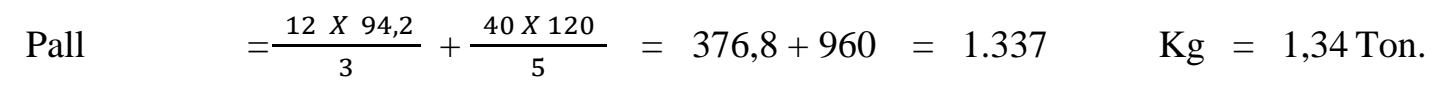

- Kedalaman 2,

Meter

$=3.399 \mathrm{Kg} .=3,40$ Ton.

- Kedalaman

Meter

$=4.204 \mathrm{Kg} .=4,20$ Ton.

- Kedalaman

4,8 Meter

$=5655 \mathrm{Kg} .=5,66$ Ton.

- Kedalaman 6 Meter

$=7014 \mathrm{Kg} .=7,01$ Ton.

- Kedalaman 7,2 Meter

$=8550 \mathrm{Kg} .=8,55$ Ton.

- Kedalaman 8,4 Meter

- Kedalaman 9,6 Meter

$=11515 \mathrm{Kg}$. = 11,52 Ton.

$=12231 \mathrm{Kg} .=12,23$ Ton.

Tabel 7. Perhitungan Daya Dukung Pondasi.

\begin{tabular}{|c|c|c|c|c|c|}
\hline $\begin{array}{c}\text { Depth } \\
(\mathrm{M})\end{array}$ & Qc & Tf & Ap & Ast & Pall \\
\hline 1,2 & 35 & 40 & 94 & 120 & 1,34 \\
\hline 2,4 & 15 & 122 & 94 & 120 & 3,40 \\
\hline 3,6 & 7 & 166 & 94 & 120 & 4,20 \\
\hline 4,8 & 15 & 216 & 94 & 120 & 5,66 \\
\hline 6 & 17 & 270 & 94 & 120 & 7,01 \\
\hline 7,2 & 17 & 334 & 94 & 120 & 8,55 \\
\hline 8,4 & 35 & 434 & 94 & 120 & 11,52 \\
\hline 9,6 & 15 & 490 & 94 & 120 & 12,23 \\
\hline
\end{tabular}

Sumber : Analisa Perhitungan Daya Dukung Pondasi. 


\subsection{Perhitungan Daya Dukung Pondasi Tiang Kelompok.}

Tahap selanjunya dilakukan perhitungan daya dukung tiang kelompok. Pile cap direncanakan bertujuan untuk mengikat dan mempersatukan tiang-tiang. Penurunan total (St) tiang kelompok harus memenuhi syarat aman $<15+600$ / B Cm, [18].

Pengurangan daya dukung kelompok tiang yang disebabkan oleh group action biasanya dinyatakan dalam suatu angka efisiensi. Perhitungan efisiensi kelompok tiang disini berdasarkan rumus Converse-Labbarredari Uniform Building Code AASHTO yaitu :

$$
\operatorname{Eg}=1-\theta \frac{(n-1) m+(m-1) n}{90 n m}
$$

Dari hasil penghitungan yang dilakukan kemudian mendapatkan hasil seperti dibawah ini :

$$
\begin{array}{ll}
\mathrm{Eg} & =1-\theta \frac{(\mathrm{n}-1) \mathrm{m}+(\mathrm{m}-1) \times \mathrm{n}}{90 \times \mathrm{m}} \\
\mathrm{Eg} & =1-21,8 \frac{(2-1) 2+(2-1) \times 2}{90 \times 2 \times} 2 \\
\mathrm{Eg} & =1-21,8 \frac{2+2}{360} \\
\mathrm{Eg} & =1-21,80,011 \\
\mathrm{Eg} & =1-0,242 \\
\mathrm{Eg} & =0,8
\end{array}
$$

Daya dukung Vertical kelompok tiang adalah :

$$
\begin{array}{lllllll}
= & \text { Eg } \times \text { Jumlah Tiang } \times \text { Daya Dukung Tiang } \\
= & 0,8 \times & 4 & \times & 12,23=37 & \text { Ton. }
\end{array}
$$

\subsection{Kontrol Daya Dukung Pondasi.}

Daya dukung pondasi harus lebih besar dari pada beban yang dipikul oleh pondasi tersebut dan penurunan yang terjadi harus sesuai batas yang diizinkan (toleransi) yaitu 1" $(2,54 \mathrm{~cm})$. [20] Maka daya dukung pondasi didapat $=37$ Ton $>$ Beban $=36$ Ton (oke). 


\section{KESIMPULAN}

Berdasarkan hasil dari penelitian berikut ini, penulis mendapatkan hasil kesimpulan dengan sebagai berikut :

1. Hasil perhitungan daya dukung tiang tunggal berdasarkan data sondir adalah sebesar 12.23 Ton, pada kedalaman 9.6 Meter.

2. Hasil perhitungan daya dukung pondasi tiang kelompok berdasarkan data sondir adalah sebesar 37 Ton.

3. Pondasi yang digunakan pada Gedung rektorat Universitas Darul Ulum Jombang direncanakan menggunakan tiang pancang dengan diameter $30 \mathrm{Cm}$, kedalaman 9.6 Meter

4. Daya dukung pondasi tiang pancang adalah 37 Ton lebih besar dari pada beban yang menumpu pada pondasi yaitu sebesar 36 Ton.

\section{SARAN}

Adapun saran yang dapat penulis sampaikan berdasar hasil dari penelitian berikut adalah bahwa sebelum melakukan perhitungan hal utama hendaknya memperoleh data teknis yang lengkap, karena data tersebut sangat membantu dalam membuat perencanaan analisa perhitungan, sesuai dengan standar, syarat-syarat dan peraturan-peraturan. Semoga karya ilmiah ini bermanfaat bagi para akademisi maupun teknisi.

\section{UCAPAN TERIMA KASIH}

Penulis ingin berterima kasih kepada Universitas Kadiri, khususnya Fakultas Teknik yang telah memberi kesempatan untuk melakukan penelitian ini. 


\section{DAFTAR PUSTAKA}

[1] M. Dewi, "Pengaruh Kualitas Pelayanan dan Fasilitas Perpustakaan terhadap Prestasi Belajar Mahasiswa Universitas Samudra," J. Manaj. dan Keuang., vol. 4, no. 1, pp. 203213, 2015.

[2] B. Santoso, R. Hidayah, and Sumadjito, "Pola Pemanfaatan Ruang Terbuka Hijau Pada Kawasan Perkampungan Plemburan Tegal, Ngaglik Sleman," INERSIA, vol. 8, no. 1, pp. 1-14, 2012, doi: 10.21831/inersia.v8i1.3694.

[3] O. Saputra and R. Lisiswanti, "Faktor-faktor yang mempengaruhi keberhasilan pembelajaran keterampilan klinik di Institusi Pendidikan Kedokteran," Juke Unila, vol. 5, no. 9, pp. 104-109, 2015, doi: 10.1063/1.4885046.

[4] M. Novita, "Sarana Dan Prasarana Yang Baik Menjadi Bagian Ujung Tombak Keberhasilan Lembaga Pendidikan Islam," NUR EL-ISLAM J. Pendidik. dan Sos. Keagamaan, vol. 4, no. 2, pp. 97-129, 2017.

[5] B. Chairullah, "Analisa Daya Dukung Pondasi Dengan Metoda SPT, CPT, dan Mayerhoff pada Lokasi Rencana Konstruksi PLTU Nagan Raya Provinsi Aceh," Teras J., vol. 3, no. 1, pp. 15-24, 2013.

[6] S. Susanto, "PERBANDINGAN FUNGSI KEANGGOTAAN TIPE SEGITIGA DAN TIPE GBELLTERHADAPANALISIS RISIKO,” vol. 3, no. 2, pp. 57-67, 2019.

[7] A. I. Candra, A. Yusuf, and A. R. F, "Studi Analisis Daya Dukung Pondasi Tiang Pada Pembangunan Gedung Lp3M Universitas Kadiri," J. CIVILA, vol. 3, no. 2, p. 166, 2018, doi: 10.30736/cvl.v3i2.259.

[8] A. I. Candra, S. Anam, Z. B. Mahardana, and A. D. Cahyono, "STUDI KASUS STABILITAS STRUKTUR TANAH LEMPUNG PADA JALAN TOTOK KEROT KEDIRI MENGGUNAKAN LIMBAH KERTAS," Ukarst J. Univ. Kadiri Ris. Tek. Sipil, vol. 2, no. 2, pp. 88-97, 2018.

[9] I. Ismael, "Keterlambatan Proyek Konstruksi Gedung Faktor Penyebab dan Tindakan Pencegahannya," Momentum, vol. 14, no. 1, pp. 46-56, 2013.

[10] M. Kalalo, "ANALISIS STABILITAS DINDING PENAHAN TANAH (STUDI KASUS: SEKITAR AREAL PT. TRAKINDO, DESA MAUMBI, KABUPATEN MINAHASA UTARA)," Sipil Statik, vol. 5, no. 5, pp. 285-294, 2017.

[11] B. A. Wiratmoko, S. Winarto, and Y. C. S. P, "PERENCANAAN PONDASI TIANG PANCANG GEDUNG KETAHANAN PANGAN NGANJUK," Jurmateks, vol. 2, no. 1, pp. 106-120, 2019.

[12] S. S. Zainal Arifin, Suyadi, "Analisis Struktur Gedung POP Hotel Terhadap Beban Gempa Dengan Metode Pushover Analysis," Jrsdd, vol. 3, no. 2, pp. 427-440, 2015.

[13] R. I. Kurniawan, A. Ridwan, S. Winarto, and A. I. Candra, "PERENCANAAN PONDASI TIANG ( Studi Kasus HOTEL MERDEKA TULUNGAGUNG )," Jurmateks, vol. 2, no. 1, pp. 144-153, 2019.

[14] F. Febriantoro, Y. C. S. P, and A. R. A, "STUDY PERENCANAAN PONDASI TIANG PANCANG JEMBATAN SEMBAYAT BARU II KECAMATAN MANYAR, KABUPATEN GRESIK," Jurmateks, vol. 1, no. 1, pp. 148-159, 2018.

[15] C. Witriyatna, A. Purnomo, Dwi, B. W, Agung, and M. Marinda, "Analisis Perbandingan Modul Jembatan Gelagar I Sebagai Fungsi Jembatan Jalan Raya Comparison Analysis of I Girder Bridge Module and Steel Box Girder As a Function of Road Bridge," vol. 12, no. 2, pp. 115-126, 2016. 
[16] A. I. Candra, "ANALISIS DAYA DUKUNG PONDASI STRAUSS PILE PADA PEMBANGUNAN GEDUNG MINI HOSPITAL UNIVERSITAS KADIRI," Ukarst, vol. 1, no. 1, pp. 63-70, 2017.

[17] Badan Standardisasi Nasional Indonesia, "Standar Perencanaan Ketahanan Gempa untuk Struktur Bangunan Gedung Sni-1726-2002.” 2002.

[18] D. Kartikasari, D. Sanhadi, P. Studi, T. Sipil, F. Teknik, and U. Islam, "STUDI EVALUASI PONDASI TIANG PANCANG ( SPUN PILE ) DENGAN PONDASI TIANG BOR ( BORED PILE ) PADA GEDUNG KANTOR," UKaRsT, vol. 3, no. 2, pp. 31-39, 2019.

[19] A. Pamungkas and E. Harianti, Desain Pondasi Tahan Gempa Sesuai SNIO3-1726-2002 dan SNI 03-2847-2002. 2002.

[20] N. Renna, "Penyesuaian Antara Pondasi Dengan Tanah Dan Beban-Bebannya." 2016. 